\title{
Bisphosphonates suppress periosteal osteoblast activity independently of resorption in rat femur and tibia
}

\author{
Ken Iwata, Jiliang Li, Helene Follet, Roger J. Phipps, David B. Burr * \\ Indiana University School of Medicine, IN 46202, USA
}

Received 15 September 2005; revised 14 April 2006; accepted 3 May 2006

\begin{abstract}
Recent studies demonstrate that bisphosphonates suppress bone resorption by leading to apoptosis of the osteoclast and inhibiting the differentiation to mature osteoclasts. The influence of bisphosphonates on bone formation is unknown, although it has been hypothesized that bisphosphonates inhibit osteoblast apoptosis and stimulate osteoblast proliferation and differentiation in vitro, leading to increased bone formation. The purpose of this study was to investigate the effect of bisphosphonates on bone formation. We administered risedronate at $0.05,0.5$ or $5.0 \mu \mathrm{g} / \mathrm{kg} / \mathrm{day}$ or alendronate at $0.1,1.0$ or $10 \mu \mathrm{g} / \mathrm{kg} /$ day subcutaneously for 17 days to 6-month-old female Sprague-Dawley rats. Control rats were given a daily subcutaneous injection of saline. Following sacrifice, the femoral and tibial mid-diaphyses were harvested and mineralizing surface (MS/BS), mineral apposition rate (MAR) and bone formation rate (BFR/BS) were measured on periosteal and endocortical surfaces. In the femur, periosteal MAR was significantly lower in all treatment groups (22-29\% for risedronate, $26-36 \%$ for alendronate) than in control. In the tibia, periosteal MAR and BFR of all treatment groups were significantly lower (41-50\% for risedronate, $43-52 \%$ for alendronate) than in the control group. Because the periosteal surfaces of these bones are only undergoing bone formation in modeling mode, our results show that bisphosphonates suppress bone formation independently of bone resorption. Because this effect is seen on periosteal MAR rather than on periosteal MS/BS, we hypothesize that bisphosphonates affect the activity of individual osteoblasts at the cell level. This may help to explain the reason that the anabolic effects of teriparatide are blunted when administered concurrently with or following a course of bisphosphonates in humans.
\end{abstract}

(C) 2006 Elsevier Inc. All rights reserved.

Keywords: Rodent; Modeling and remodeling; Osteoblast; Bone histomorphometry

\section{Introduction}

The nitrogen-containing bisphosphonates, alendronate and risedronate, suppress bone turnover, increase bone mass (primarily through increases in mineralization) and reduce fracture risk in osteoporotic women $[5,6,8,17,31,39]$. They act by promoting osteoclast apoptosis and inhibiting differentiation to mature osteoclasts $[16,25,30,32,40,41]$ or by reducing osteoclast activity $[2,10,11,15,31,38,40,44]$, either through an inhibition of farnesyl diphosphonate synthase (FPP) in the mevalonate pathway, or by otherwise inhibiting prenylation of small GTPases. The influence of bisphosphonates on bone formation is unknown, although it has been hypothesized, based primarily on studies in culture, that bisphosphonates inhibit osteoblast apoptosis [1,35,38] and may

\footnotetext{
* Corresponding author.

E-mail address: dburr@iupui.edu (D.B. Burr).
}

stimulate osteoblast proliferation and differentiation $[18,19,23$, $26,41,42]$, leading to increased bone formation.

Studies in animal models have produced equivocal results. In ovariectomized rats, risedronate had no effect on tibial periosteal surface apposition, and suppressed bone formation on the tibial endosteal surface $[2,43]$. In intact growing rats, on the other hand, alendronate significantly suppressed mineral apposition rate and bone formation rate on the periosteal surface of the tibia [3]. Furthermore in OPG knock-out mice, risedronate markedly suppressed both periosteal and endocortical mineral apposition rate [33]. These data suggest that bisphosphonates may suppress bone formation independently of bone resorption.

Specific effects of bisphosphonates on osteoblast activity and bone formation are difficult to test on remodeling surfaces where resorption and formation are coupled because suppression of bone turnover naturally reduces both bone resorption and bone formation. However, the periosteal 
surface of bone in mature rats does not undergo appreciable resorption but rather is known to undergo direct bone apposition in modeling mode. Based on data from the literature that suggested that bisphosphonates inhibit osteoblast apoptosis, we hypothesized that bisphosphonates would enhance periosteal bone formation. We tested this hypothesis by evaluating the effects of risedronate and alendronate on bone formation on periosteal surfaces known to be undergoing modeling formation in adult rats.

\section{Materials and methods}

Six-month-old female Sprague-Dawley rats $(n=62)$ (Harlan, Indianapolis, IN, USA) were housed two per cage at Indiana University's Laboratory Animal Resource Center. Animal rooms were environmentally controlled at a temperature of $67-77^{\circ} \mathrm{F}$ and a relative humidity of $30-70 \%$. A light cycle of $12 \mathrm{~h}$ light and $12 \mathrm{~h}$ dark maintained. Water and standard rat feed were provided ad libitum during the acclimation and experimental periods. All procedures were approved by Indiana University's Institutional Animal Care and Use Committee.

Rats were divided by weight into 7 groups. Control rats (CNT; $n=9)$ were given a daily subcutaneous (sc) injection of saline vehicle. Six groups of rats were injected subcutaneously daily for 17 days with risedronate (RIS) in a saline carrier at a dose of $0.05 \mu \mathrm{g} / \mathrm{kg}$ per day (RIS-low; $n=9$ ), $0.5 \mu \mathrm{g} / \mathrm{kg}$ per day (RISmid; $n=9$ ) or $5 \mu \mathrm{g} / \mathrm{kg}$ per day (RIS-high; $n=9$ ); or alendronate (ALN) at a dose of $0.1 \mu \mathrm{g} / \mathrm{kg}$ per day (ALN-low; $n=9$ ), $1.0 \mu \mathrm{g} / \mathrm{kg}$ per day (ALN-mid; $n=8$ ) or $10 \mu \mathrm{g} / \mathrm{kg}$ per day (ALN-high; $n=9$ ). The middle doses are equivalent to the therapeutic dose used clinically. Drug dosages were designed for dose equivalence based on the relative potency of risedronate and alendronate.

All rats were given an intraperitoneal (ip) injection of calcein $(10 \mathrm{mg} / \mathrm{kg}$ body mass; Sigma Chemical Co., St. Louis, MO, USA) on days 8 and 3 prior to killing. The right femurs and tibias were removed and cleaned of soft tissue. The diaphyses were dehydrated in graded alcohols, cleared in xylene and embedded in methylmethacrylate. Using a diamond-embedded wire saw (Histo-saw; Delaware Diamond Knives, Wilmington, DE, USA), transverse thick sections $(70 \mu \mathrm{m})$ were removed from the middle of the diaphyses and mounted unstained on standard microscope slides. Histomorphometric parameters were measured at $100 \times$ magnification from two slides per limb on a Nikon Optiphot fluorescence microscope (Nikon, Inc., Garden City, NY, USA) using the Bioquant digitizing system (R\&M Biometrics, Nashville, TN, USA). Total bone perimeter (B.Pm), single-label perimeter (sL.Pm) and double-label perimeter (dL.Pm) were measured on periosteal and endocortical surfaces at $100 \times$ magnification. Double-label area (dL.Ar) was collected at $200 \times$ magnification. Primary data were averaged for calculation of the derived parameters: mineralizing surface (MS/bone surface $[\mathrm{BS}]=[1 / 2 \mathrm{sL} . \mathrm{Pm}+\mathrm{dL} . \mathrm{Pm}] / \mathrm{B} . \mathrm{Pm} ; \%)$; mineral apposition rate $(\mathrm{MAR}=\mathrm{dL} . \mathrm{Ar} / \mathrm{dL} . \mathrm{Pm}$ per 5 days; $\mu \mathrm{m} / \mathrm{day}) ;$ and bone formation rate $(\mathrm{BFR} /$ $\mathrm{BS}=\mathrm{MAR} \times \mathrm{MS} / \mathrm{BS} \times 3.65 ; \mu \mathrm{m}^{3} / \mu \mathrm{m}^{2} /$ year). Terminology is in accordance with the American Society for Bone and Mineral Research (ASBMR) committee on histomorphometric nomenclature [34]. Statistical tests were performed using SAS software (SAS Institute, Inc.). Differences among treatment groups were evaluated using a one-way analysis of variance (ANOVA). When a significant overall $F$ value $(P<0.05)$ was present, differences between individual group means were tested using Fisher's protected least-significant difference (PLSD) post hoc test. For all tests, $P<0.05$ was considered statistically significant. Data are presented as mean \pm standard deviation.

\section{Results}

There was a significant reduction in mineral apposition rate on the periosteal surfaces of both the femur and tibia at all doses of both bisphosphonates. On the femoral periosteal surface, this reduction ranged from $21 \%$ to $29 \%$ for risedronate and between

\section{A}

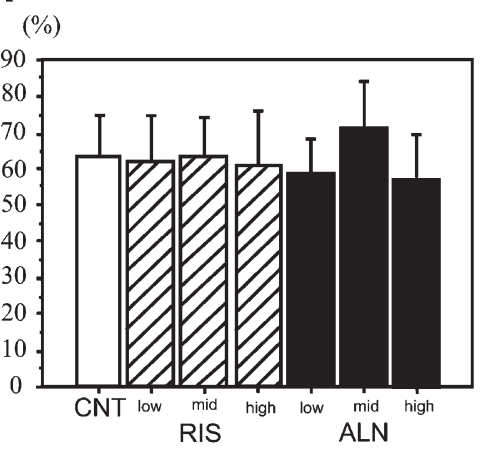

MS/BS

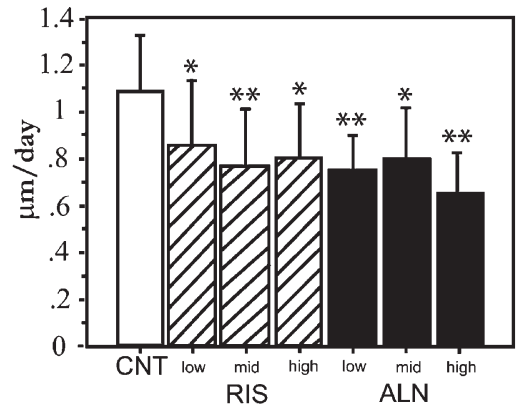

MAR

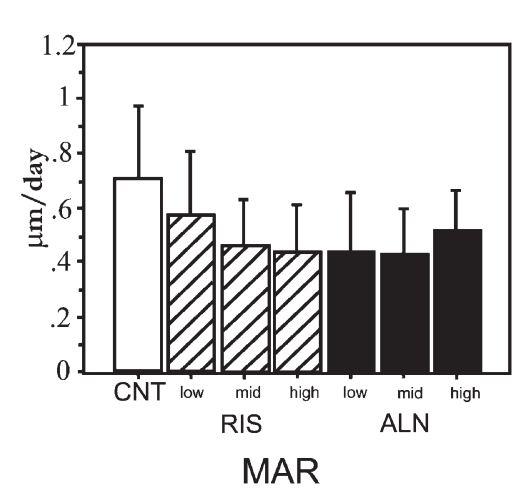

MAR

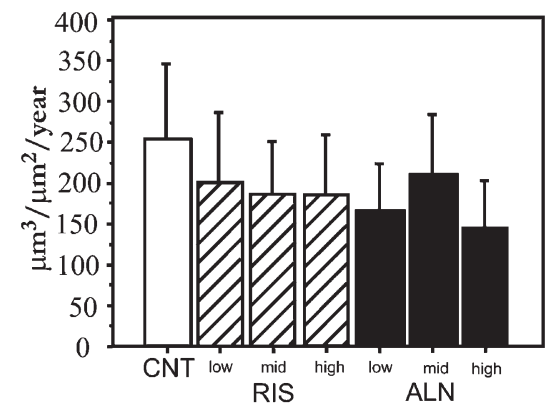

BFR/BS

B

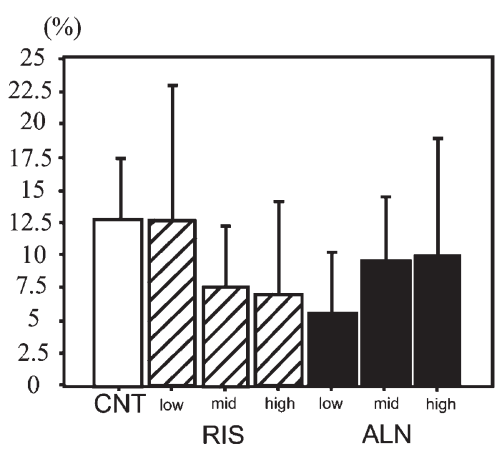

MS/BS

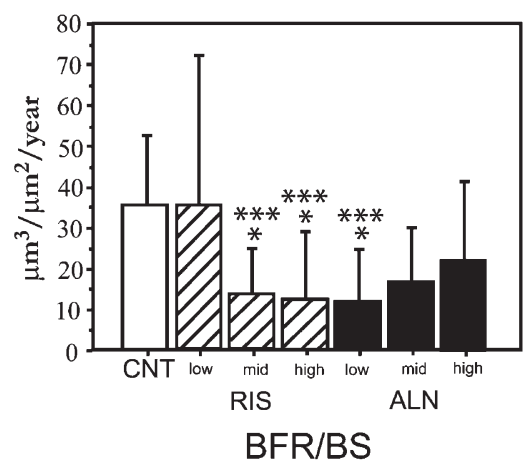

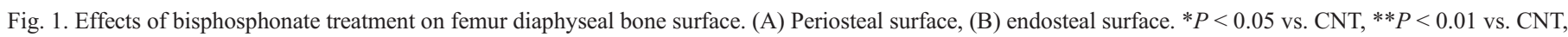
$* * * P<0.05$ vs. RIS-low. 
26 and 36\% for alendronate (Figs. 1 and 3A). On the tibial periosteal surface, the reduction was slightly greater than in the femur, ranging from $41 \%$ to $50 \%$ for risedronate and $43 \%$ to $52 \%$ for alendronate (Figs. 2 and 3B). For the tibial periosteal surface, but not for the femoral periosteal surface, this translated into a significant depression of bone formation rate. There were no significant differences between bisphosphonate-treated groups.

On endocortical surfaces, significant suppression compared to control animals was found only in bone formation rate in the femur (Fig. 1). This suppression ranged between $61 \%$ and $67 \%$. No significant differences among groups were found for femoral MS/BS or MAR on the endocortical surface, nor were any significant differences found on the endocortical surface of the tibia (Fig. 2). Again, no significant differences were found between risedronate and alendronate-treated groups.

\section{Discussion}

Our data show that the bisphosphonates at clinical dose levels as well as lower levels significantly suppress bone formation independent of that found from coupled bone remodeling. This suppression was primarily found for mineral apposition rate, which is generally considered as an indicator of individual celllevel activity. No significant suppression was found for mineralizing surface, suggesting that bisphosphonates may not have a suppressive effect on osteoblast proliferation or differentiation but rather only on the individual activity of osteoblasts.
It is not certain whether the bisphosphonates suppress osteoblast activity through direct action on the osteoblast itself, or only indirectly through osteoclast regulation of osteoblast activity. Several studies show in vitro a direct effect of bisphosphonates on osteoblast proliferation and differentiation, independent of any effects that may occur through suppression of bone resorption. However, these studies differ on exactly how bisphosphonates may affect these cell-level processes, showing either an inhibitory effect on both proliferation and differentiation [27], a stimulatory effect $[18,19,23,26,42]$, a stimulatory effect on differentiation, but a suppressive effect on proliferation [37], or no effect on either [20]. It is well known that osteoclasts ingest large amounts of bisphosphonates released from resorbed bone matrix, and that this prevents protein prenylation necessary for their proper function $[10,11]$. Direct effects of bisphosphonates on non-resorbing cells, including osteoblasts in culture, have been reported [12], although this apparently conflicts with data from the same group that suggests that risedronate, at least, is not internalized by osteoblasts [13]. Even if osteoblasts do internalize bisphosphonate, they do not internalize much [12] and because bisphosphonates cannot be metabolized by the osteoblast their intracellular concentration could increase over time. It is still possible that even a small amount of drug could interfere with cell function. Indeed, Gasser et al. [21] observed that bisphosphonates are able to prevent protein prenylation in osteoblasts.

Osteoprotegerin (OPG) production in osteoblasts, which is stimulated by bisphosphonates [41], also has a function in auto-

A
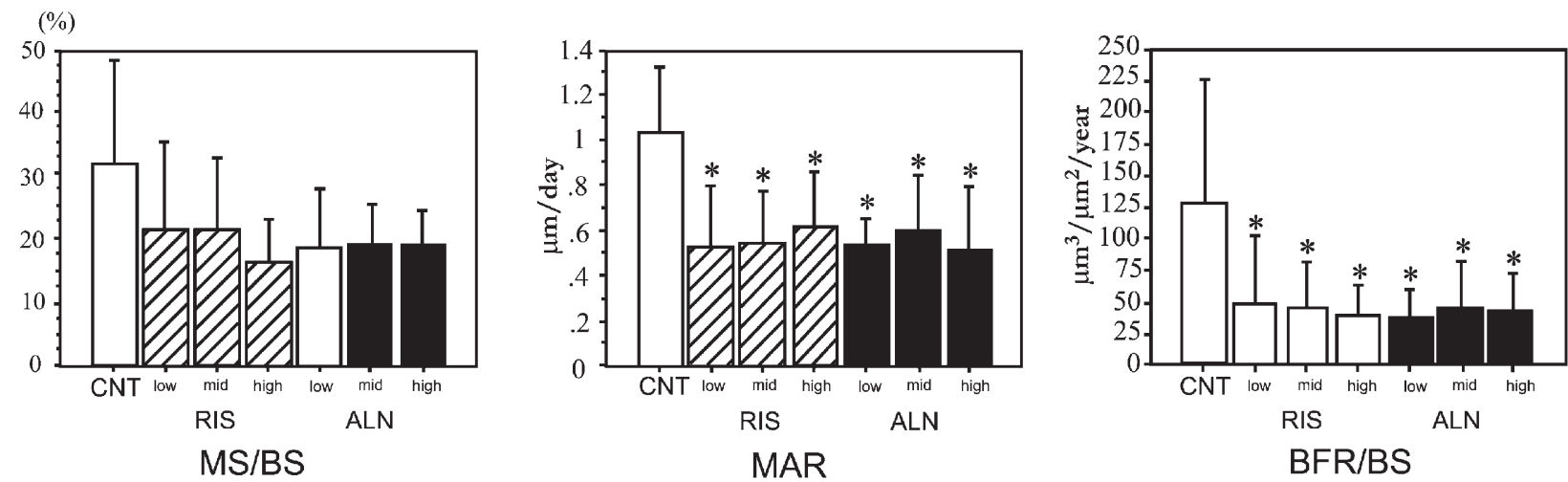

\section{B}

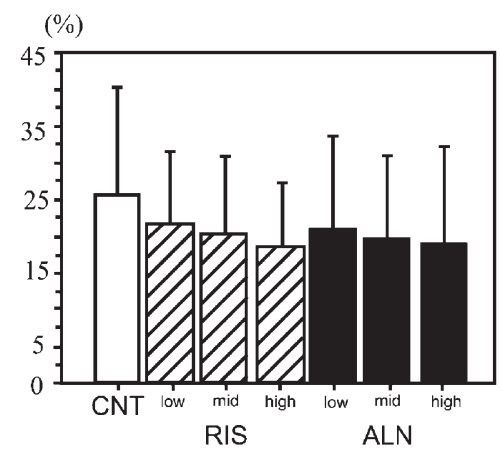

MS/BS
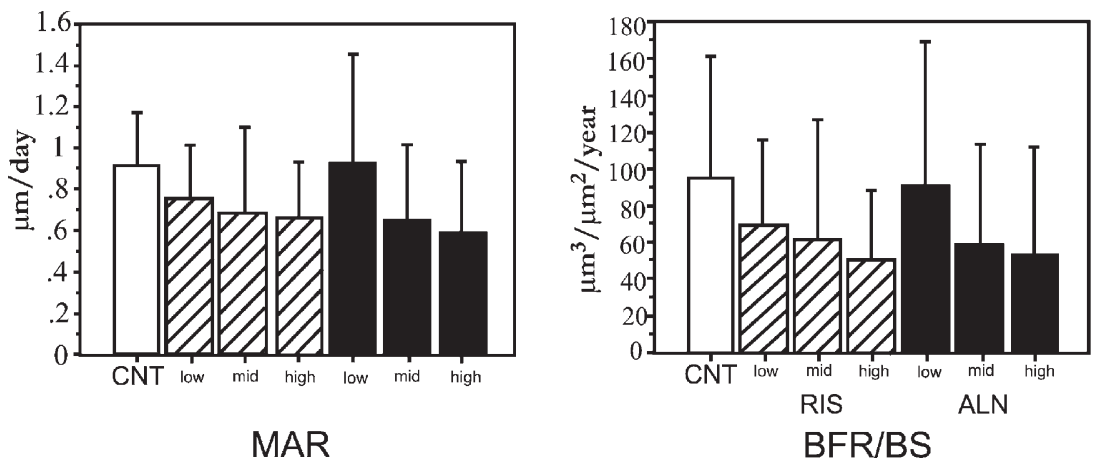

Fig. 2. Effects of bisphosphonates treatment on tibia diaphyseal bone surface. (A) Periosteal surface, (B) endosteal surface. ${ }^{*} P<0.01$ vs. CNT. 
A

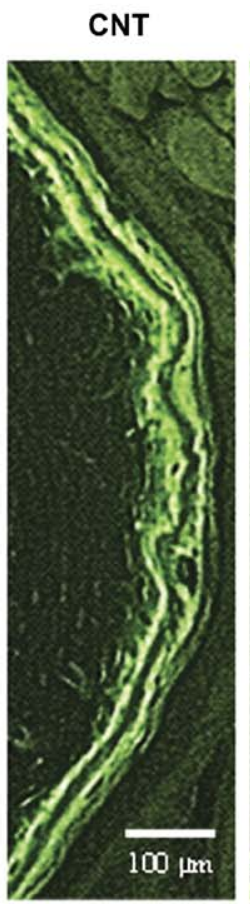

RIS-low

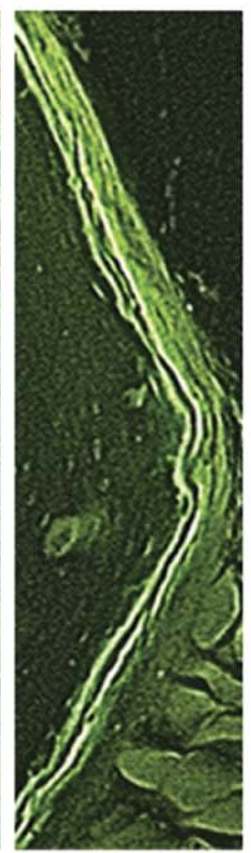

RIS-mid

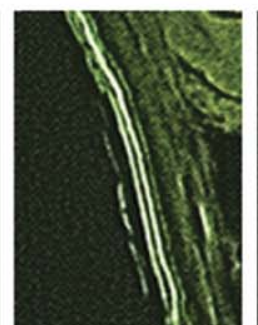

B

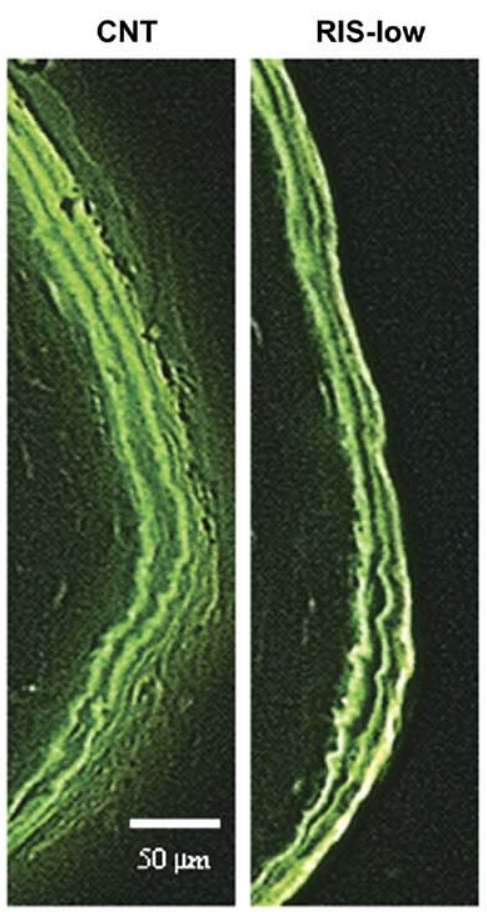

RIS-mid

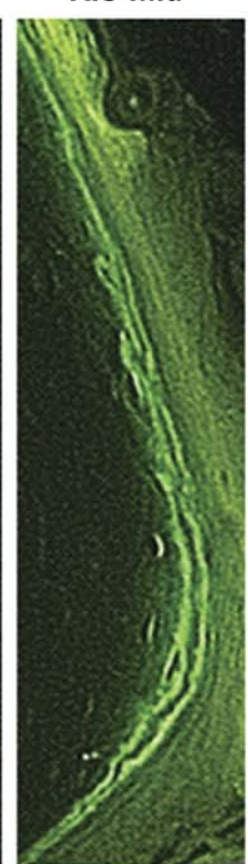

RIS-high

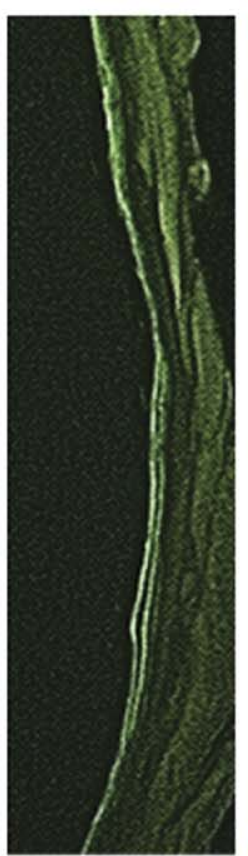

ALN-low

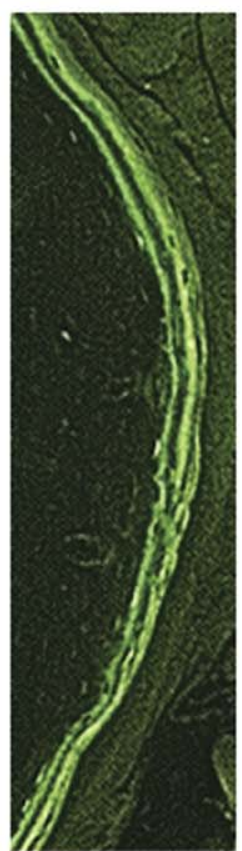

ALN-mid

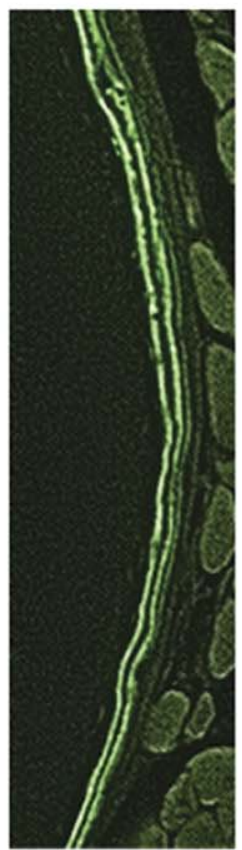

ALN-high

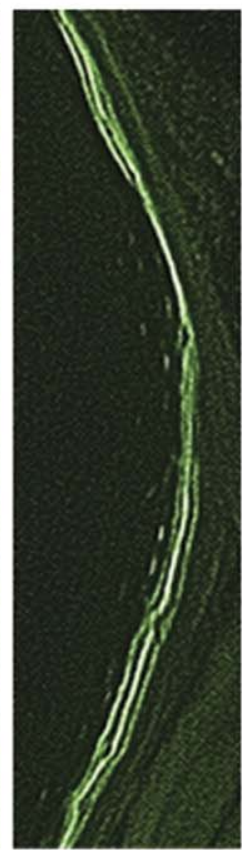

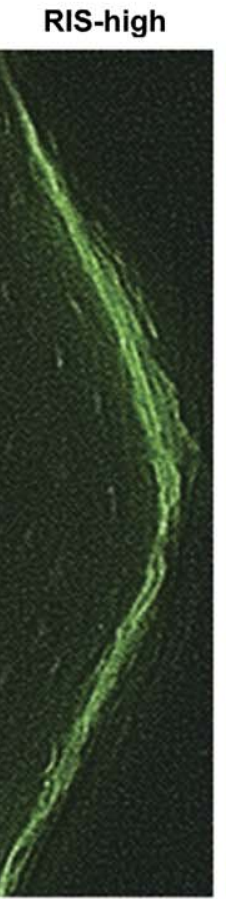
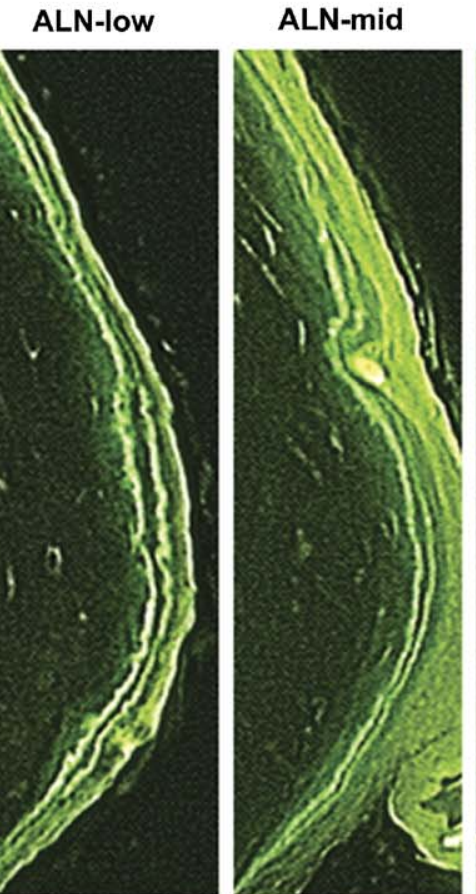

ALN-high

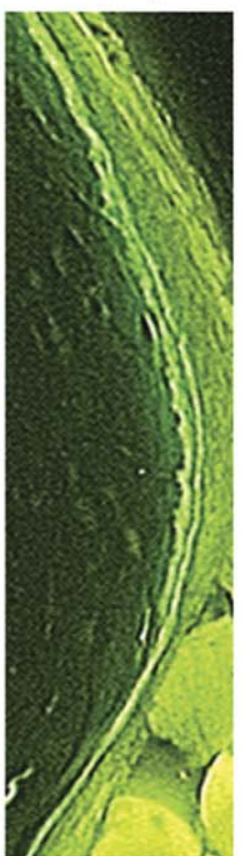

Fig. 3. Periosteal surface from cross section of diaphysis. (A) Femur, original magnification: $\times 100$. (B) Tibia, original magnification: $\times 200$.

regulation of osteoblastic bone formation. Nakamura et al. [33] showed that mineral apposition rate was significantly increased in OPG knock-out mice, but that this elevation of MAR was decreased in $\mathrm{OPG}^{-}-1-$ when risedronate was administered at $0.01 \mathrm{mg} / \mathrm{kg} /$ day for 30 days. This suppression of osteoblast function occurred without any change in the RANKL-RANK interaction. They also observed that risedronate treatment al- tered osteoblast shape from more cuboidal, typical of an active osteoblast, to flatter, more typical of a lining cell or a quiescent osteoblast. They suggest that osteoclasts regulate osteoblast function directly. This regulation could occur even at a remote site not undergoing coupled remodeling.

These results may in part explain why the anabolic effects of teriparatide are blunted by concurrent $[4,15]$ or prior [14] 
administration of bisphosphonates in humans. One explanation for the attenuation of teriparatide effects by bisphosphonates is that as bone formation is reduced as a consequence of lower activation frequency, there are fewer mature osteoblasts available for teriparatide to stimulate [28]. We offer the alternative explanation that bisphosphonates impair the activity of individual cells and make them less receptive to stimulation by teriparatide. We found no evidence of a suppressive effect of alendronate on bone's mineralizing surface (MS/BS), which would be indicative of fewer available fully differentiated osteoblasts, but only an effect to suppress mineral apposition rate. This is consistent with the observation of Gasser et al. [22] who showed reduced MAR in rats pre-treated with alendronate and then subsequently treated with PTH. Gasser et al. suggested that this blunting effect could occur through a direct effect on the lining cells, which do not convert to active osteoblasts because of the inhibitory effect of bisphosphonates on cytoskeletal function. This explanation coincides nicely with the observation of Nakamura et al. [33] that risedronate caused de-differentiation of active osteoblasts to flatter cells more typical of lining cells. Gasser et al, however, also showed that a two-month alendronate withdrawal period to allow washout of the drug prior to the initiation of PTH treatment did not restore the normal anabolic response to PTH. This suggests that there is also a recurring suppression of bone formation caused by continuing interaction of matrix embedded drug on the lining cells or active osteoblasts. This matrix interaction effect could still occur through direct influence on the osteoblast, independent of the effect on the portion of bone formation that occurs as the result of coupled remodeling.

It is known that there is an "anabolic window" following the initiation of teriparatide therapy. This is caused by an uncoupling of resorption and formation that allows formation to occur through direct apposition of bone to trabecular and periosteal surfaces [24,29] 3-4 months before the rise in coupled remodeling [7]. This may be one reason that teriparatide treatment following pretreatment with alendronate has its greatest attenuating effects within the first 6 months of teriparatide treatment [14].

This effect on bone formation also may help to explain the failure to find consistent increases in bone volume following treatment with bisphosphonates [9,36]. Indeed, Boivin et al. [5] have proposed that the prolonged period of secondary mineralization and increased mean tissue age caused by the bisphosphonates can account for almost all of the increased BMD observed over the first 3 years of treatment. One might expect that suppression of bone resorption by alendronate would nevertheless allow the refilling of the remodeling space by osteoblastic bone formation, resulting in a $3-5 \%$ increase in bone volume. However, this has been difficult to detect from human biopsy studies [9,36]. An independent suppressive effect on osteoblasts at the BMU level could account for the absence of these changes in bone volume.

In this study, we showed that bisphosphonates suppress bone formation on periosteal surfaces that are modeling in formation mode. This may indicate a direct effect on osteoblast activity and suppression of bone formation independently of bone resorption, but an indirect effect dependent on suppression of resorption at remote sites and perhaps mediated through OPG cannot be excluded. Regardless of which of these mechanisms is correct, the simple observation that bisphosphonates can have a suppressive effect on bone formation provides an explanation for the observation that the anabolic effects of teriparatide are blunted when administered in conjunction with bisphosphonate treatment in human patients.

\section{Acknowledgments}

The authors would like to acknowledge Dr. Keith W. Condon for histological preparation. Support for this work was provided by The Alliance for Better Bone Health.

\section{References}

[1] Abe Y, Kawakami A, Nakashima T, Ejima E, Fujiyama K, Kiriyama T, et al. Etidronate inhibits human osteoblast apoptosis by inhibition of proapoptotic factor(s) produced by activated T cells. J Lab Clin Med 2000;136: 344-54.

[2] Baumann BD, Wronski TJ. Response of cortical bone to antiresorptive agents and parathyroid hormone in aged ovariectomized rats. Bone 1995;16: 247-53.

[3] Bikle DD, Morey-Holton ER, Doty SB, Currier PA, Tanner SJ, Halloran BP. Alendronate increases skeletal mass of growing rats during unloading by inhibiting resorption of calcified cartilage. J Bone Miner Res 1994;9:1777-87.

[4] Black DM, Greenspan SL, Ensrud KE, Palermo L, McGowan JA, Lang TF, et al. The effects of parathyroid hormone and alendronate alone or in combination in postmenopausal osteoporosis. N Engl J Med 2003;349:1207-15.

[5] Boivin GY, Chavassieux PM, Santora AC, Yates J, Meunier PJ. Alendronate increases bone strength by increasing the mean degree of mineralization of bone tissue in osteoporotic women. Bone 2000;27:687-94.

[6] Bone HG, Hosking D, Devogelaer JP, Tucci JR, Emkey RD, Tonino RP, et al. Ten years' experience with alendronate for osteoporosis in postmenopausal women. N Engl J Med 2004;350:1189-99.

[7] Burr DB. Does early PTH treatment compromise bone strength? The balance between remodeling, porosity, bone mineral, and bone size. Curr Osteoporosis Reports 2005;3:19-24.

[8] Burr DB, Miller L, Grynpas M, Li J, Boyde A, Mashiba T, et al. Tissue mineralization is increased following 1-year treatment with high doses of bisphosphonates in dogs. Bone 2003;33:960-9.

[9] Chavassieux PM, Arlot ME, Reda C, Wei L, Yates AJ, Meunier PJ. Histomorphometric assessment of the long-term effects of alendronate on bone quality and remodeling in patients with osteoporosis. J Clin Invest 1997; 100:1475-80.

[10] Coxon FP, Helfrich MH, Larijani B, Muzylak M, Dunford JE, Marshall D, et al. Identification of a novel phosphonocarboxylate inhibitor of rab geranylgeranyl transferase that specifically prevents Rab prenylation in osteoclasts and macrophages. J Biol Chem 2001;276:48213-22.

[11] Coxon FP, Ebentino FH, Mules EH, Seabra MC, McKenna CE, Rogers MJ. Phosphonocarboxylate inhibitors of Rab geranylgeranyl transferase disrupt the prenylation and membrane localization of Rab proteins in osteoclasts in vitro and in vivo. Bone 2005;37:349-58.

[12] Coxon FP, Thompson K, Ebetino FH, Rogers MJ. Resorbing osteoclasts increase the availability of mineral-bound bisphosphonates to nonresorbing cells. J Bone Miner Res 2005;20:s260.

[13] Coxon FP, Thompson K, Hughes A, Ebetino FH, Rogers MJ. Risedronate and other nitrogen-containing bisphosphonates are efficiently internalized from mineralized surfaces by osteoclasts, but not other cell types, in vitro and in vivo. Bone 2005;36:s303.

[14] Ettinger B, San Martin J, Crans G, Pavo I. Differential effects of teriparatide on BMD after treatment with raloxifene or alendronate. J Bone Miner Res 2004;19:745-51.

[15] Finkelstein JS, Hayes A, Hunzelman JL, Wyland JJ, Lee H, Neer RM. The effects of parathyroid hormone, alendronate, or both in men with osteoporosis. N Engl J Med 2003;349:1216-26.

[16] Fisher JE, Rodan GA, Reszka AA. In vivo effects of bisphosphonates on the osteoclast mevalonate pathway. Endocrinology 2000;141:4793-6. 
[17] Follet H, Boivin G, Rumelhart C, Meunier PJ. The degree of mineralization is a determinant of bone strength: a study on human calcanei. Bone 2004;34:783-9.

[18] Frediani B, Spreafico A, Capperucci C, Chellini F, Gambera D, Ferrata P, et al. Long-term effects of neridronate on human osteoblastic cell cultures. Bone 2004;35:859-69.

[19] Fromigue O, Body JJ. Bisphosphonates influence the proliferation and the maturation of normal human osteoblasts. J Endocrinol Invest 2002;25:539-46.

[20] Garcia-Moreno C, Serrano S, Nacher M, Farre M, Diez A, Marinoso ML, et al. Effect of alendronate on cultured normal human osteoblasts. Bone 1998;22:233-9.

[21] Gasser JA, Ingold P, Rebmann A, Susa M. The blunting of the bone anabolic response to PTH observed after frequently dosed bisphosphonates in rats may be explained by inhibition of farnesyl diphosphate synthase in osteoblasts. J Bone Miner Res 2005;20:s78.

[22] Gasser JA, Kneissel M, Thomsen JS, Mosekilde L. PTH and interactions with bisphosphonates. J Muscloskel Neuron Interact 2000;1:53-6.

[23] Giuliani N, Pedrazzoni M, Negri G, Passeri G, Impicciatore M, Girasole G. Bisphosphonates stimulate formation of osteoblast precursors and mineralized nodules in murine and human bone marrow cultures in vitro and promote early osteoblastogenesis in young and aged mice in vivo. Bone 1998;22:455-61.

[24] Hodsman AB, Steer BM. Early histomorphometric changes in response to parathyroid hormone therapy in osteoporosis: evidence for de novo bone formation on quiescent cancellous surfaces. Bone 1993;14:523-7.

[25] Hughes DE, Wright KR, Uy HL, Sasaki A, Yoneda T, Roodman GD, et al. Bisphosphonates promote apoptosis in murine osteoclasts in vitro and in vivo. J Bone Miner Res 1995;10:1478-87.

[26] Im GI, Qureshi SA, Kenney J, Rubash HE, Shanbhag AS. Osteoblast proliferation and maturation by bisphosphonates. Biomaterials 2004;25:4105-15.

[27] Khokher MA, Dandona P. Diphosphonates inhibit human osteoblast secretion and proliferation. Metabolism 1989;38:184-7.

[28] Khosla S. Parathyroid hormone plus alendronate - a combination that does not add up. N Engl J Med 2003;349:1277-9.

[29] Lindsay RZH, Cosman F, Bosteom M, Cruz JD, Nieves JW, Dempster DW. Short term response to parathyroid hormone (1-34 hPTH) in human iliac crest bone using a unique quadruple (double double) tetracycline labeling regimen and single biopsy. J Bone Miner Res 2003;18:s54.

[30] Mackie PS, Fisher JL, Zhou H, Choong PF. Bisphosphonates regulate cell growth and gene expression in the UMR 106-01 clonal rat osteosarcoma cell line. Br J Cancer 2001;84:951-8.

[31] Meunier PJ, Boivin G. Bone mineral density reflects bone mass but also the degree of mineralization of bone: therapeutic implications. Bone 1997;21:373-7.
[32] Murakami H, Takahashi N, Sasaki T, Udagawa N, Tanaka S, Nakamura I, et al. A possible mechanism of the specific action of bisphosphonates on osteoclasts: tiludronate preferentially affects polarized osteoclasts having ruffled borders. Bone 1995;17:137-44.

[33] Nakamura M, Udagawa N, Matsuura S, Mogi M, Nakamura H, Horiuchi $\mathrm{H}$, et al. Osteoprotegerin regulates bone formation through a coupling mechanism with bone resorption. Endocrinology 2003;144:5441-9.

[34] Parfitt AM, Drezner MK, Glorieux FH, Kanis JA, Malluche H, Meunier PJ, et al. Bone histomorphometry: standardization of nomenclature, symbols, and units. Report of the ASBMR Histomorphometry Nomenclature Committee. J Bone Miner Res 1987;2:595-610.

[35] Plotkin LI, Weinstein RS, Parfitt AM, Roberson PK, Manolagas SC, Bellido T. Prevention of osteocyte and osteoblast apoptosis by bisphosphonates and calcitonin. J Clin Invest 1999;104:1363-74.

[36] Recker REK, Diem S, Cheng E, Bare S, Masarachia P, Roschger P, et al. Normal bone histomorphometry and 3D microarchitecture after 10 years alendronate treatment of postmenopausal women. J Bone Miner Res 2004;19: s45.

[37] Reinholz GG, Getz B, Pederson L, Sanders ES, Subramaniam M, Ingle $\mathrm{JN}$, et al. Bisphosphonates directly regulate cell proliferation, differentiation, and gene expression in human osteoblasts. Cancer Res 2000;60: 6001-7.

[38] Rodan GA, Fleisch HA. Bisphosphonates: mechanisms of action. J Clin Invest 1996;97:2692-6.

[39] Sorensen OH, Crawford GM, Mulder H, Hosking DJ, Gennari C, Mellstrom $\mathrm{D}$, et al. Long-term efficacy of risedronate: a 5-year placebo-controlled clinical experience. Bone 2003;32:120-6.

[40] van beek E, Lowik C, van der Pluijm G, Papapoulos S. The role of geranylgeranylation in bone resorption and its suppression by bisphosphonates in fetal bone explants in vitro: a clue to the mechanism of action of nitrogen-containing bisphosphonates. J Bone Miner Res 1999; 14:722-9.

[41] Viereck V, Emons G, Lauck V, Frosch KH, Blaschke S, Grundker C, et al. Bisphosphonates pamidronate and zoledronic acid stimulate osteoprotegerin production by primary human osteoblasts. Biochem Biophys Res Commun 2002;291:680-6.

[42] von Knoch F, Jaquiery C, Kowalsky M, Schaeren S, Alabre C, Martin I, et al. Effects of bisphosphonates on proliferation and osteoblast differentiation of human bone marrow stromal cells. Biomaterials 2005;26:6941-9.

[43] Wronski TJ, Yen CF. Anabolic effects of parathyroid hormone on cortical bone in ovariectomized rats. Bone 1994;15:51-8.

[44] Zimolo Z, Wesolowski G, Rodan GA. Acid extrusion is induced by osteoclast attachment to bone. Inhibition by alendronate and calcitonin. J Clin Invest 1995;96:2277-83. 